\title{
RESEARCHING THE PERFORMANCE OF DUAL-CHAMBER FIRE-TUBE BOILER FURNACE
}

\author{
Sergei Khaustov ${ }^{1, a}$, Yana Belousova ${ }^{1}$ \\ ${ }^{1}$ National Research Tomsk Polytechnic University, 634050 Tomsk, Russia
}

\begin{abstract}
Autonomous heating systems equipped with fire-tube or shell boilers show high effectiveness, consistent performance and great technical parameters. But there is a significant limitation of its thermal productivity due to the complexity of durable large diameter fire-tube bottoms implementation. Optimization of combustion aerodynamics can be the way to expand the fire-tube boilers performance limit. In this case lots of problems connected with reducing emissions of toxic substances, providing of burning stability, local heat stresses and aerodynamic resistances should be solved. To resolve the indicated problems, a modified model of dual-chamber fire-tube boiler furnace is proposed. The performance of suggested flame-tube was simulated using the proven computer-aided engineering software ANSYS Multiphysics. Results display proposed flame tube completely filled with moving medium without stagnant zones. Turbulent vortical combustion is observed even with the straightthrough fuel supply. Active flue gas recirculation in suggested dual-chamber furnace reduces emissions of pollutants. Diminution of wall heat fluxes allows boiler operation at lower water treatment costs.
\end{abstract}

\section{Introduction}

Fire-tube boilers (or shell boilers) presently have a main concern among heating equipment. Particular qualities of such boilers let it to be applied in autonomous heating systems, providing customers with thermal energy, apart from utility companies and commercial enterprises. This equipment shows high effectiveness, consistent performance and great technical parameters. These and other particular qualities resulted to the overall using of fire-tube boilers in heat-supply systems over the world [1 - 4]. Most frequently used layout is a single fire-tube boiler [2]. But cylindrical steam boilers with two or more fire tubes are also used (e.g., Lancashire boilers used on railway locomotives) [3]. Design of low power boilers (mainly with the fire-tube heating surfaces) requires organizing of minimum gas and water paths dynamic resistance, optimal combustion characteristics and environmental friendliness.

Basing on decades of experience with fire-tube boilers performance is possible to assert that their main problem is a significant limitation of the thermal productivity [1]. The power of these boilers is hardly limited by dimensions of the furnace due to the complexity of durable large diameter fire-tube bottoms implementation [1]. At the same time shell boilers has higher useful surface per $\mathrm{m}^{3}$ of gas volume compared to water tube analogs and as a result, superior performance at the same dimensions [1].

Limit of fire-tube boilers performance can be increased by setting more powerful burners with additional optimization of combustion aerodynamics. In this case lots of problems connected with reducing emissions of

a Corresponding author: khaustovsa@tpu.ru

This is an Open Access article distributed under the terms of the Creative Commons Attribution License 4.0, which permits unrestricted use, distribution, and reproduction in any medium, provided the original work is properly cited. 


\section{MATEC Web of Conferences}

toxic substances, providing of burning stability, local heat stresses and aerodynamic resistances will invariably encounter $[5,6]$.

\section{Object of study}

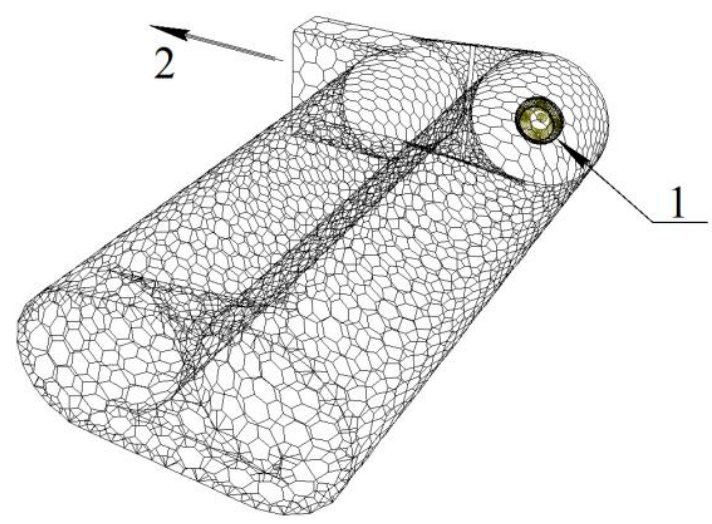

Figure 1. Computational mesh of the investigated combustion chamber with the partition into polyhedral finite elements: 1 - burner (inlet of air-fuel mixture); 2 - outlet of combustion products

To resolve the indicated problems, a modified model of the furnace (Fig. 1) is proposed. It is identical to a known furnace layout of Lancashire boiler [3] wherein two cylindrical flame tubes are interconnected in the both front (frontal interconnection) and rear (impasse interconnection) segments. Only one cylindrical flame tube is equipped with a burner, which is situated in the frontal part. Gas flow linearly moves along the first flame tube until changing its direction to the second flame tube at an impasse interconnection. The reaction zone is located in the first cylindrical chamber between its bottom and the burner slot (1).

For additional transfer of the combustion products into the second flame tube there is frontal interconnection between two cylindrical chambers, it creates a flow in a direction opposite to the fuel supply, thus generating a vortical motion. In this way proposed layout makes possible turbulent combustion with the straight-through fuel supply.

Experimental tests of the suggested dual-chamber fire-tube boiler furnace (detailed multivariable research of turbulent combusting) require a lot of time and money. Therefore numerical simulation using approved software today is the most widespread way for combuster aerodynamics design and optimization $[5,7]$. In this paper for the study and analysis of gas dynamics and thermal processes in the dual-chamber fire-tubes ANSYS Multiphysics engineering software was applied as a research tool.

For the numerical simulation, full geometrical model of suggested dual-chamber fire-tube boiler furnace was implemented. A computational mesh (Fig. 1) designed using ANSYS Workbench contains $10^{5}$ polyhedral cells, with $7.6 \mathrm{~m}^{3}$ aggregated interior volume. Boundary conditions were set for 8700 wall faces, 2187 inlet faces and 32 outlet faces.

\section{Results}

According to the numerical investigation of suggested dual-chamber furnace computer model using software ANSYS Multiphysics and proven mathematical methods $[2,8]$ next results were found. At the outlet of the burner nozzle zones of reduced pressure are formed. It generates flue gases recirculation to the flame root (fig. 2), which looks similar to combustion organization with a reversed flame [2].

The fuel mixture is supplied to the reaction area at the first cylindrical chamber, wherein it is combusted. Combustion products are separated into two flows. First flow directly moves to second flame tube through the impasse interconnection channel. Remaining flow recirculates to the burner orifice and leaves the first chamber through the frontal channel, generating in the reaction area axisymmetric torus-shaped turbulent vortices (fig.2). Recirculating motion is not stationary-closed: gaseous medium moves inside the vortices with twisted spiral trajectories to frontal interconnection channel (fig. 2). 

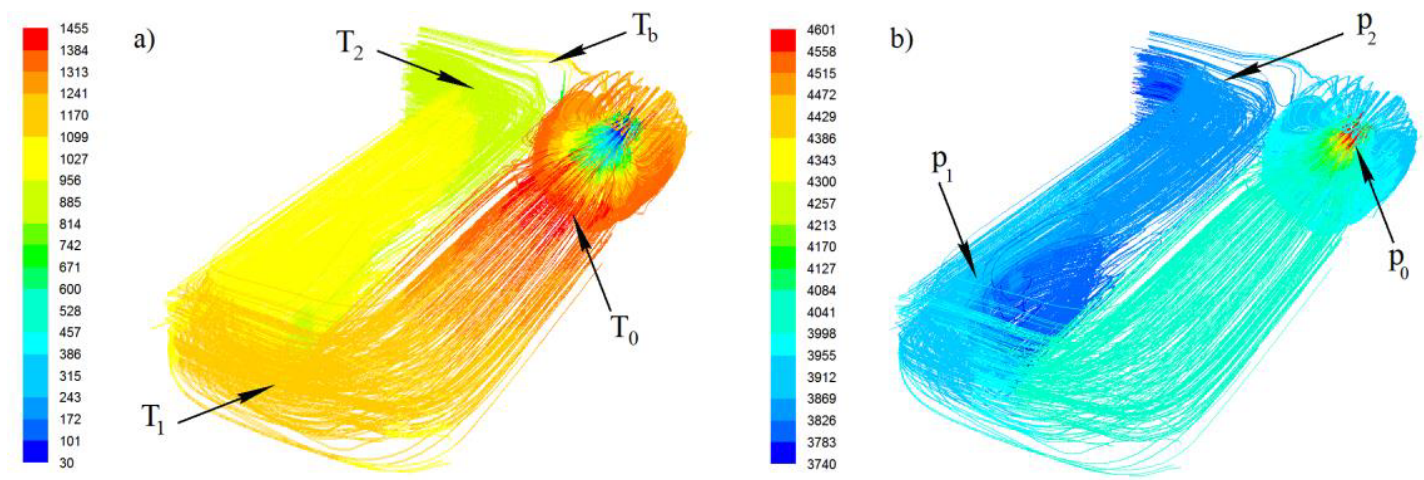

Figure 2. Computer simulation results: a - pathlines colored by mean temperature values $\left({ }^{\circ} \mathrm{C}\right) ; \mathrm{b}$ - pathlines colored by total gauge pressure values $(\mathrm{Pa})$

Nomenclature: $\mathrm{T}_{0}$ - combustion temperature; $\mathrm{T}_{\mathrm{b}}$ - flue gases temperature in the frontal interconnection channel; $T_{1}$ - flue gases temperature in the impasse interconnection channel; $T_{2}$ - flue gases temperature on the furnace outlet; $\mathrm{p}_{0}$ - total gauge pressure in the reaction region; $\mathrm{p}_{1}$ - total gauge pressure in the impasse interconnection channel; $p_{2}$ - total gauge pressure on the furnace outlet (after frontal and impasse interconnection flows mixing); $F_{b}, F_{1}-$ flow area $\left(\mathrm{m}^{2}\right)$ of the frontal and impasse interconnection channels respectively.

The direct and recirculating flows will move from the first cylindrical flame tube into the second one through different interconnection channels, wherein the mass flow rate will be determined by characteristics of the appropriate channel (fig. 2). Pressure loss in the frontal interconnection channel is equal to the pressure difference $\mathrm{p}_{0}-\mathrm{p}_{1}$ and corresponds to the total flow resistance of the first and second processes of the flue gases movement (numerically is $0.82 \mathrm{kPa}$ ).

Vortex structure lies between two opposing coaxial currents (fuel-air mixture jet and recirculating flue gases) and represents a multiple torus-shaped vortices whose rotation axis coincides with the axis of the first cylindrical flame tube. Vortex structures consist of gases with the combustion temperature $\mathrm{T}_{0}$ (fig.2), because high turbulent kinetic energy values in vortex cause intensive inflammation on its boundaries. With suggested aerodynamics by heat exchange between the flame and the adjacent vortex one portion of the combustion heat leaves the first cylindrical chamber with the flue gases through the impasse interconnection channel, and the remaining heat portion due to recirculation is back into the burner jet. As the result, the jet of fuel-air mixture is heated by thermal conduction and turbulent diffusion of recirculating flue gases.

\section{Discussion}

In described vortical aerodynamics fuel-air mixing occurs not only inside the burner but also in the volume of the first cylindrical flame tube. In this way suggested dual-chamber fire-tube boiler furnace layout makes possible the turbulent combustion in the vortex with the straight-through fuel supply. Consequently inflammation in twisted medium is accelerated, the reaction rate increases, flare dimensions are reduced, and as a result, the production of furnace requires less metal. Moreover active flue gas recirculation reduces emissions of harmful to the environment nitrogen oxides $[5,6]$.

Suggested combustion chamber completely filled with moving medium without stagnant zones. Uniformly distributed heat release leads to low heat fluxes through the screening surfaces. That is beneficial for reliable boiler operating and, especially, for reduction of scale formation [9]. Therefore diminution of wall heat fluxes allows boiler operation at lower water treatment costs.

According to the results of numerical simulation the following conclusions are made:

- In the proposed dual-chamber fire-tube furnace all basic aerodynamic features of reversed flame will be observed, since, by analogy with the reversing aerodynamics implementation the combustion is arranged in the oncoming flows of fuel-air mixture and recirculated flue gases.

- Combination of direct flow fuel-air mixture supply with the vortical aerodynamics in the mixing region creates optimum conditions for effective and ecological combustion with minimum flow resistance. This intensification of air-fuel mixing advances at, firstly, reducing the flare range and, secondly, exclusion of flame pouncing on the heating surfaces.

- For design and engineering calculations of the considered combustion chamber the proportion of flue gases recirculating through the frontal interconnection is an important criterion, which directly effects on the rate 


\section{MATEC Web of Conferences}

of heat transfer from the flame, the turbulence characteristics, combustion temperature and the rate of nitrogen oxides emission.

For the described layout there are approximate equations of quasi-one dimensional method of recirculating fraction calculation applied to the combustion chamber with reversed flame [10]. In order to estimate the impact of the recirculating flue gases on the integral boiler performance characteristics in paper [10] is suggested to use the relative value of the recirculation flow ( $r$ ). It can be defined as volumetric flow rate of the recirculating flue gases divided by total volume flow through the furnace:

$$
r=\frac{a}{1+a}
$$

ratio $a$ can be defined as volumetric flow rate of the flue gases passing through frontal interconnection channel $\left(V_{b}\right)$ divided by the volumetric flow rate through impasse interconnection channel $\left(V_{1}\right)$. Substituting $\zeta_{\mathrm{b}}, \zeta_{1}-$ flow resistance coefficients for frontal and impasse interconnection channels respectively, ratio $a$ can be calculated with this formula:

$$
a=\sqrt{\frac{\zeta_{1} \cdot T_{1}}{\zeta_{b} \cdot T_{b}}} \cdot \frac{F_{b}}{F_{1}}
$$

Since the recirculation vortex consists of the combustion products came out of the reaction area, the heat loss of the flame can be defined as the multiplication of recirculation flow relative value ( $r$ ) by enthalpy of the combusting medium with the mean temperature $\mathrm{T}_{0}$ (fig. 2). Interrelation between frontal and impasse connection channels gaseous medium characteristics can be estimated with this equation [10]:

$$
\frac{V_{b} \cdot T_{b}}{F_{b} \cdot 273}=\sqrt{\frac{\zeta_{1} \cdot T_{b}}{\zeta_{b} \cdot T_{1}}} \cdot \frac{V_{1} \cdot T_{1}}{F_{1} \cdot 273}
$$

\section{Conclusion}

According to the results of the study there are following advantages of the proposed fire-tube furnace layout:

- the uniform heat dissipation along the length of the flame reduces local heat fluxes through the heating surfaces, it favorably affects the reliability and service life of the boiler;

- straight-through fuel supply combined with the turbulent aerodynamics in proposed fire-tube furnace creates the most favorable conditions for the complete fuel combustion with minimal flow resistance;

- twisting in the recirculation vortex significantly intensifies the ignition and combustion, thus decreasing metal consumption of the boiler by reducing the furnace length;

- intensive heat dissipation in the flame causes mean temperature decreasing in the reaction area, it is advantageous for reducing the emission of thermal nitrogen oxides and makes possible using of cheaper materials for heating surfaces.

The reported study was partially supported by the Ministry of education and science of The Russian Federation (Government Order No. 13.948.2014/K and Government Order No. 2069).

\section{References}

1. Historical Advancement of Fire-Side Heating Surface in Fire-Tube Boilers (American Boiler Manufacturers Association, Arlington, Va., USA, 2004)

2. A.S. Zavorin, S.A. Khaustov, N.A. Zaharushkin, IOP Conference Series: Materials Science and Engineering 66 (1), 012029 (2014)

3. The British Railway Locomotive, 1803-1853. Science Museum. 1958. ISBN 0-11-290152-2.

4. R.B. Tabakaev, A.V. Kazakov, A.S. Zavorin, Solid Fuel Chem., 49, 267 (2015).

5. Y.E. Boke, O. Aydin, H.D. Yildizay, Energy Sources, Part A: Recovery, Utilization, and Environmental Effects 33: 13, 1271 (2011)

6. M.A. Habib, M. Elshafei, and M.Dajani, Comput. Fluids 37, 12 (2008) 
7. K. Sorensen, T. Condra, N. Houbak, C. Karstensen, Modelling and Simulating Fire Tube Boiler Performance (44th Conference on Simulation and Modeling, Malardalen University, Vasteres, Sweden, 2003)

8. A.S. Zavorin, S.A. Khaustov, N.A. Zaharushkin, Proc. of 2014 Int. Conf. on Mechanical Engineering, Automation and Control Systems (Russia: Tomsk/Institute of Electrical and Electronics Engineers Inc.), 6986908 (2014)

9. S.A. Khaustov, A.S. Zavorin, K.V. Buvakov, V.A. Sheikin, EPJ Web of Conferences 82, 01039 (2015)

10. S.A. Khaustov, A.S. Zavorin, K.V. Buvakov, N.A. Zakharushkin, MATEC Web of Conferences 19, 01020 (2014) 